\title{
Produção e avaliação de briquetes de resíduos lignocelulósicos
}

\author{
Luana Elis de Ramos e Paula ${ }^{1}$, Paulo Fernando Trugilho¹, Raphael Nogueira Rezende ${ }^{1}$ Claudinéia Olímpia de Assis ${ }^{1}$, \\ Ana Elisa Rodarte Baliza ${ }^{1}$ \\ ${ }^{1}$ Universidade Federal de Lavras - UFLA, Departamento de Ciências Florestais, CP 3037, CEP 37200-000, Lavras, Minas Gerais, Brasil
}

"Autor correspondente:

luanafloresta@hotmail.com

Termos para indexação:

Energia

Biomassa

Briquetagem

Index terms:

Energy

Biomass

Briquetting

Histórico do artigo:

Recebido em 28 mar 2011

Aprovado em 28 jun 2011

Publicado em 30 jun 2011
Resumo - O objetivo deste trabalho foi produzir e avaliar briquetes de resíduos de biomassa vegetal e testar diferentes tempos e temperaturas de briquetagem para alguns deles. O material utilizado foi resíduos do processamento da madeira (maravalha e serragem); pergaminho do grão e caule do cafeeiro; caule e vagem do feijão; caule e vagem da soja; casca de arroz; folha, caule, palha e sabugo de milho e palha e bagaço de cana-de-açúcar. A briquetagem foi realizada à pressão de 150 Bar. Foram testados diferentes tempos de briquetagem para a serragem da madeira e diferentes temperaturas para a casca do arroz e para o pergaminho do café. Na avaliação da qualidade dos briquetes, determinaram-se a densidade relativa aparente, a resistência à compressão e o índice de combustão. Os resultados indicaram que o tempo e a temperatura de briquetagem interferiram na resistência mecânica dos briquetes. O melhor tempo de prensagem foi de 8 minutos e a temperatura de $125^{\circ} \mathrm{C}$. Os briquetes da casca de arroz apresentaram maior densidade e alta resistência mecânica. O maior índice de combustão foi encontrado para os briquetes da vagem do feijão.

\section{Production and evaluation of lignocellulosic residue briquettes}

\begin{abstract}
This study aimed to produce and evaluating the briquettes made from residues of plant biomass and test different times and temperatures. The material utilized was composed of wood processing residues (wood shaving and sawdust), coffee bean parchment and coffee tree stem, beam stem and pod, soybean stem and pod, rice husk, corn leaf, stem, straw and cob and sugar cane straw and bagasse. Briquetting was performed at a pressure of 150 Bar. Different times were tested for briquetting sawdust from wood and different temperatures for rice husk and parchment coffee. For evaluation of the briquettes quality, the apparent relative density, compression resistance and combustion index were determined. The results indicated that the briquetting time and temperature interfered in the mechanical resistance of the briquettes. The best pressing time was of eight minutes and the temperature of $125^{\circ} \mathrm{C}$. The briquettes produced from rice husk presented higher density and high mechanical density. The highest combustion index was found for the bean pod briquettes.
\end{abstract}




\section{Introdução}

A discussão sobre formas alternativas de energia é de grande importância para o cenário energético atual. $\mathrm{O}$ Brasil e o mundo se encontram em crescente aumento populacional, o que ocasiona maior demanda e uso de produtos energéticos.

Em 2009, a matriz energética brasileira concentrou o uso em mais de 50\% nas fontes derivadas do petróleo e eletricidade e cerca de $22 \%$ foi representado pela biomassa. O consumo das fontes energéticas lenha, carvão vegetal e derivados da cana corresponderam a $7,5 \%, 1,8 \%$ e $13 \%$, respectivamente (Brasil, 2010).

A produção e utilização dessa biomassa é responsável pela geração de uma grande quantidade de resíduos, que na maioria das vezes é depositado inadequadamente no ambiente, ocasionando impactos ambientais, perda de matéria-prima e energia.

Uma das formas de minimizar o desperdício e a pressão sobre o ambiente se dá por meio do aproveitamento dos resíduos. Nesse contexto, destaca-se a briquetagem, processo no qual resíduos lignocelulósicos, como serragem, maravalha, casca de arroz, palha de milho, sabugo, bagaço de cana, entre outros, são compactados, possibilitando seu aproveitamento como matéria-prima na substituição da lenha por um produto equivalente (Schütz et al., 2010).

Durante a briquetagem, os resíduos são densificados utilizando na maioria das vezes temperatura e pressão. De acordo com Chen et al. (2009), o aumento da temperatura faz com que a lignina se torne plástica e atue como ligante natural das partículas durante a compactação. Segundo Kaliyan \& Morey (2009), além da lignina, as proteínas, amido, gorduras e carboidratos solúveis também são adesivos naturais da biomassa. A presença destes componentes justifica a não utilização de aglomerantes artificiais para briquetagem.

Os briquetes podem dar um destino viável econômica e ambientalmente aos resíduos. Além de possuírem formato regular e constituição homogênea, o que resulta em queima uniforme do material, são de fácil manuseio e transporte, de baixa umidade e possuem maior densidade energética.

A qualidade dos briquetes é avaliada por meio de algumas características ou pelo seu comportamento durante o uso. De acordo com Quirino \& Brito (1991), os testes que avaliam as propriedades mecânicas dos briquetes são usualmente os mais empregados. A resistência à compressão, por exemplo, determina a capacidade de empilhamento na estocagem. O teste de tamboramento, ou índice de quebra e abrasão, determina a resistência à abrasão provocada durante o transporte e o manuseio natural dos briquetes. Todos estes testes medem aspectos de qualidade. No entanto, segundo os autores, esses resultados devem ser interpretados com cuidado porque são influenciados pelo tamanho e pela forma dos briquetes, e, ainda, pelas propriedades dos materiais a partir dos quais são produzidos. Para muitos propósitos, a densidade é o parâmetro de qualidade mais importante.

Para avaliar o comportamento dos briquetes em uso, Quirino \& Brito (1991) elaboraram um dispositivo de teste. Este aparelho possibilitou a verificação da temperatura e da massa consumida a cada instante durante a combustão, o que permitiu a elaboração de curvas de temperatura $\mathrm{x}$ tempo e massa $\mathrm{x}$ tempo; a partir dos valores obtidos em pontos dessas curvas elaborou-se um índice denominado "índice de combustão" ou ICOM. Briquetes com maior ICOM possuem qualidade superior, pois uma menor massa desse material seria consumida para um dado período de tempo de combustão e uma temperatura mais elevada seria atingida. Logo, para uso industrial, o ideal é que os briquetes apresentem um ICOM o mais elevado possível.

Este trabalho foi realizado com o objetivo de produzir e avaliar briquetes feitos a partir de diferentes resíduos de biomassa vegetal e testar diferentes tempos e temperaturas de briquetagem.

\section{Material e métodos}

Para a produção dos briquetes foram utilizados os resíduos do processamento da madeira (maravalha e serragem), pergaminho do grão e caule do cafeeiro, caule e vagem do feijão, caule e vagem da soja, casca de arroz, folha, caule, palha e sabugo do milho e palha e bagaço da cana-de-açúcar, todos adquiridos na cidade de Lavras, MG.

Os materiais foram levados para o Laboratório de Energia da Biomassa Florestal da Universidade Federal de Lavras. O caule do café; o caule e a vagem do feijão; o caule e a vagem da soja; a folha, o caule, a palha e o sabugo do milho e a palha da cana-de-açúcar passaram por processamento em moinho martelo. Após moagem, estes resíduos apresentaram granulometria de, aproximadamente, $4 \mathrm{~mm}$. 
A briquetadeira utilizada neste estudo é fabricada em aço inox e porcelana, com cilindro de força máxima de 10 toneladas e resistência elétrica atingindo até $300^{\circ} \mathrm{C}$.

A pressão empregada na produção dos briquetes foi de 150 Bar $\left(153 \mathrm{kgf} \mathrm{cm}^{-2}\right)$ e a quantidade de material foi limitada pelo volume do cilindro da briquetadeira utilizada.

Após a produção, os briquetes foram encaminhados para uma câmara climatizada para homogeneização da umidade, onde permaneceram até atingir massa constante. A umidade final dos briquetes foi de $12 \%$.

Os ensaios mecânicos para avaliar a resistência à compressão dos briquetes foram feitos em uma máquina universal de ensaios, de forma semelhante aos realizados por Quirino \& Brito (1991), velocidade de carregamento de $0,03 \mathrm{~cm} \mathrm{~min}^{-1}$, aplicada no sentido diametral dos briquetes.

A densidade aparente foi determinada pelo método estequiométrico, que consiste em obter o volume a partir de medições, utilizando-se um paquímetro e a massa em uma balança com precisão de $5 \mathrm{mg}$.
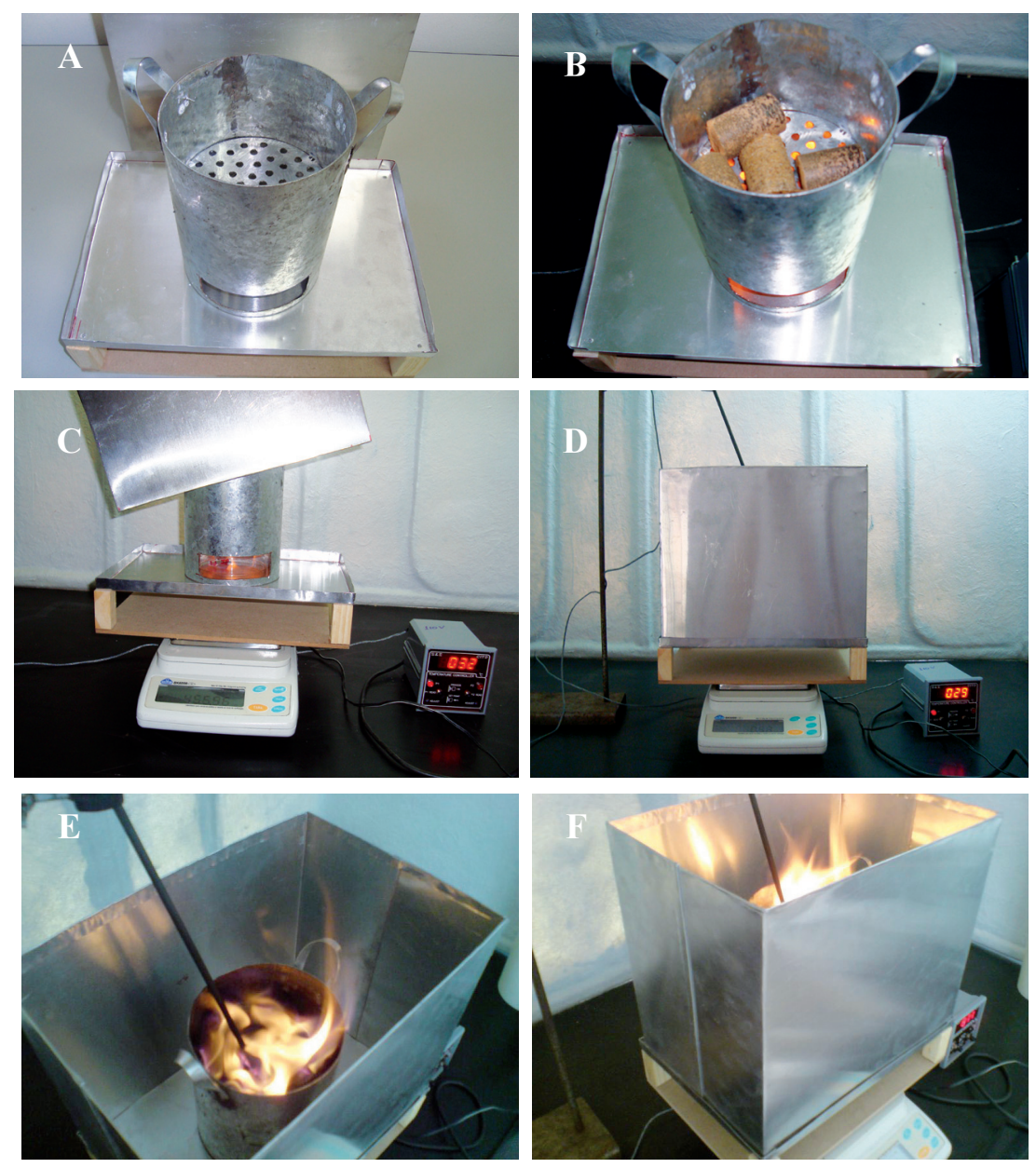

Figura 1. Funcionamento do equipamento combustor, (A) combustor; (B) combustor com briquetes e início da combustão; (C) anteparo protetor sendo colocado; (D) conjunto combustor, bases, balança e medidor de temperatura; (E) posição do sensor do medidor de temperatura; (F) combustão. 
Com o equipamento mensuraram-se a massa e a temperatura em função do tempo durante a combustão e foram construídos gráficos de tempo $\mathrm{x}$ temperatura e tempo x massa. A partir de pontos desses gráficos, calculou-se o índice de combustão (ICOM), equação 1, conforme Quirino \& Brito (1991), com algumas modificações.

$\mathrm{ICOM}=(\mathrm{A} \times \mathrm{B}) /(100 \times \mathrm{C})$

em que,

$\mathrm{A}=$ porcentagem do tempo no qual a temperatura permanece acima de $150{ }^{\circ} \mathrm{C}$, em relação ao tempo total de teste até a temperatura final de $100{ }^{\circ} \mathrm{C}$;

$\mathrm{B}=$ porcentagem da temperatura máxima atingida em relação à temperatura de $150{ }^{\circ} \mathrm{C}$;

$\mathrm{C}=$ porcentagem da massa total consumida, gerando temperaturas acima de $150{ }^{\circ} \mathrm{C}$.

A massa de briquetes utilizada neste teste foi de $(150 \pm 20)$ g. O tempo foi variável e considerou-se o intervalo que foi do início da combustão até a temperatura final de $100^{\circ} \mathrm{C}$.

Para efeito comparativo, realizou-se o ensaio de combustão em madeira maciça e carvão vegetal.

\section{Ajuste do tempo de compactação}

Inicialmente, foi realizado um experimento piloto, com diferentes tempos de compactação, em temperatura ambiente, para a obtenção do tempo de melhor desempenho na briquetagem. Utilizou-se como referência a serragem da madeira, nos tempos $2,3,4$, 5,7 e 10 minutos.

Na Tabela 1 são apresentados os valores obtidos para os ensaios dos briquetes de serragem em diferentes tempos.

Tabela 1. Densidade relativa aparente, ICOM e resistência mecânica dos briquetes, em função do tempo de briquetagem.

\begin{tabular}{|c|c|c|c|c|}
\hline Material & $\begin{array}{c}\text { Tempo } \\
\text { (min) }\end{array}$ & $\begin{array}{c}\text { Densidade } \\
\text { aparente } \\
\left(\mathrm{g} \mathrm{cm}^{-3}\right)\end{array}$ & ICOM & $\begin{array}{c}\text { Resistência } \\
\text { mecânica } \\
\left(\mathrm{kgf} \mathrm{cm}^{-2}\right)\end{array}$ \\
\hline \multirow{6}{*}{ Serragem } & 2 & 0,868 & 0,5490 & 167,74 \\
\hline & 3 & 0,885 & 0,5442 & 197,58 \\
\hline & 4 & 0,878 & 0,5207 & 211,10 \\
\hline & 5 & 0,884 & 0,5378 & 212,84 \\
\hline & 7 & 0,865 & 0,5123 & 216,27 \\
\hline & 10 & 0,883 & 0,4577 & 224,29 \\
\hline
\end{tabular}

Existe uma tendência de aumento da resistência mecânica à medida que o tempo de briquetagem aumenta. Entretanto, o mesmo não ocorreu para a densidade aparente e o ICOM (Tabela 1).

Os resultados de resistência mecânica à compressão e tempo foram utilizados para a avaliação da relação funcional (Figura 2). Foi ajustado o modelo polinomial quadrático, que apresentou o melhor ajuste.

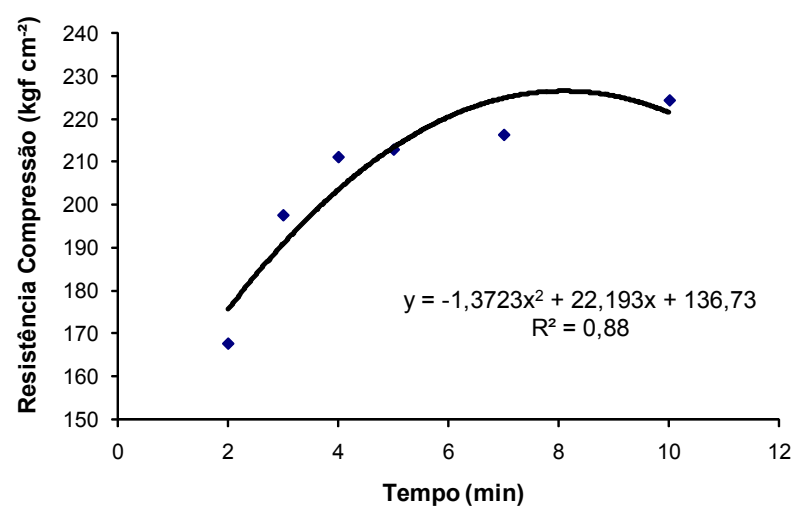

Figura 2. Resistência à compressão, em função do tempo de briquetagem.

Após o ajuste da equação de regressão (modelo quadrático), foi determinado o seu ponto crítico, sendo, neste caso, um ponto de máximo. Para obter o ponto crítico da função basta tornar $\hat{Y} \equiv 0$ (diferencial de $\hat{Y}$ identicamente nula), o que equivale resolver o seguinte sistema (Equação 2):

$$
\frac{\partial Y}{\partial X}=\mathbf{0}
$$

ou seja,

$$
(2 \times \mathbf{b} \mathbf{2}) X+\mathbf{b} \mathbf{1}=\mathbf{0}
$$

Resolvendo o sistema, encontrou-se um valor de 8,09 minutos, sendo este um ponto de máximo. Desta forma, considerou-se o tempo de 8 minutos para a confecção dos briquetes de todos os resíduos avaliados. Os briquetes que não obtiveram resultados satisfatórios, ou seja, não briquetaram e por isso não tinham condições de serem avaliados, foram produzidos com a inclusão de temperatura.

\section{Ajuste da temperatura de briquetagem}

Para os resíduos pergaminho e casca de arroz, foram utilizadas as temperaturas $110,115,120$ e $125^{\circ} \mathrm{C}$, para o ajuste da temperatura de briquetagem (Tabela 2). 
Tabela 2. Densidade relativa aparente, ICOM e resistência mecânica à compressão de briquetes produzidos em diferentes temperaturas.

\begin{tabular}{|c|c|c|c|c|}
\hline 苞 & $\begin{array}{c}\text { Temperatura } \\
\left({ }^{\circ} \mathrm{C}\right)\end{array}$ & $\begin{array}{c}\text { Densidade } \\
\text { aparente } \\
\left(\mathrm{g} \mathrm{cm}^{-3}\right)\end{array}$ & ICOM & $\begin{array}{c}\text { Resistência } \\
\text { mecânica } \\
\left(\mathrm{kgf} \mathrm{cm}^{-2}\right)\end{array}$ \\
\hline \multirow{4}{*}{ 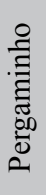 } & 110 & 0,889 & 0,4163 & 76,83 \\
\hline & 115 & 0,915 & 0,4729 & 86,38 \\
\hline & 120 & 0,913 & 0,4101 & 88,99 \\
\hline & 125 & 0,946 & 0,4546 & 115,99 \\
\hline \multirow{4}{*}{ 冚 } & 110 & 0,909 & 0,4170 & 135,82 \\
\hline & 115 & 0,997 & 0,5279 & 175,29 \\
\hline & 120 & 0,985 & 0,5254 & 199,19 \\
\hline & 125 & 1,077 & 0,4293 & 331,50 \\
\hline
\end{tabular}

Assim como no ajuste do tempo de briquetagem, o ajuste da temperatura não apresentou tendência definida para o ICOM e a densidade aparente. Dessa forma, optou-se por utilizar os resultados de resistência mecânica para a determinação da melhor temperatura de briquetagem.

Nas Figuras 3 e 4 observam-se os resultados de resistência mecânica à compressão do pergaminho e da casca de arroz, respectivamente. Foram ajustados modelos polinomiais quadráticos, de melhores performances. Os gráficos indicaram um aumento na resistência à compressão, à medida que se aumentou a temperatura para os dois resíduos, por isso, considerou-se a temperatura de $125^{\circ} \mathrm{C}$ como a de melhor desempenho. Este fato é melhor observado na Figura 4.

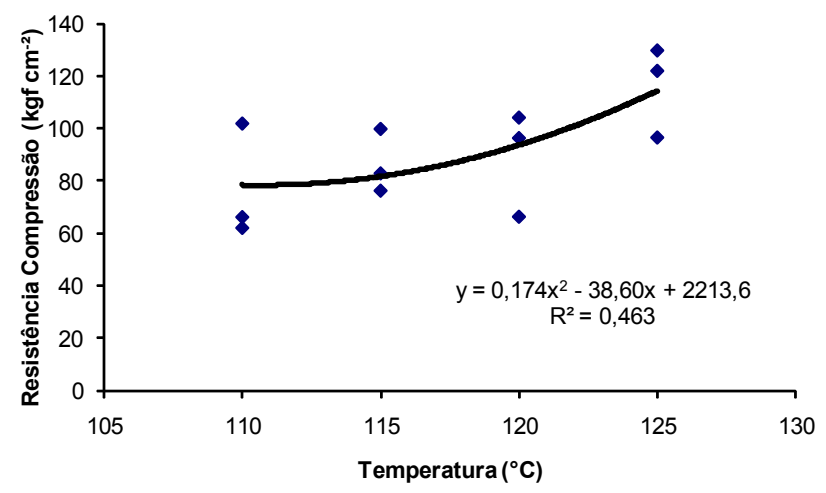

Figura 3. Resistência à compressão do briquete de pergaminho, em função da temperatura de briquetagem.

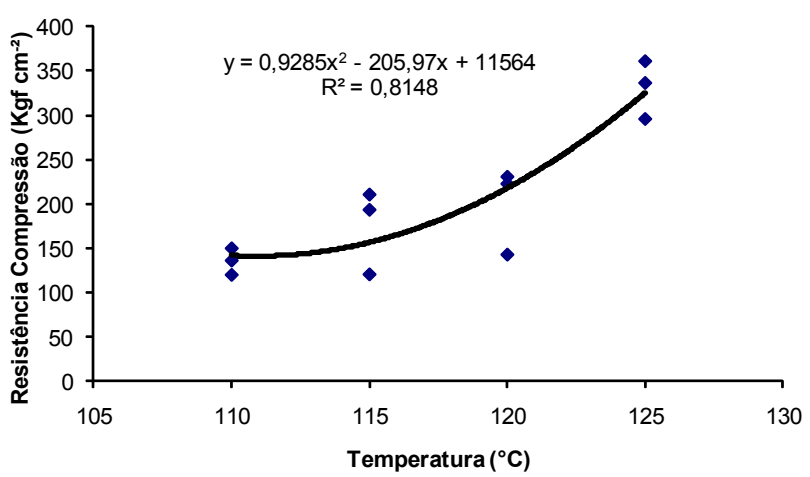

Figura 4. Resistência à compressão do briquete de casca de arroz, em função da temperatura de briquetagem.

Os gráficos das Figuras 3 e 4 indicaram um aumento na resistência à compressão à medida que se aumentou a temperatura para os dois resíduos, por isso, considerou-se a temperatura de $125^{\circ} \mathrm{C}$ como a de melhor desempenho. Este fato é melhor observado na Figura 4.

\section{Análise estatística}

O experimento foi instalado segundo um delineamento inteiramente casualizado, com diferentes números de repetição por tratamento. Para a comparação múltipla foi utilizado o teste Scott-Knott, a 5\% de significância.

\section{Resultados e discussão}

Os resultados médios das características avaliadas nos briquetes e o teste de comparação múltipla realizados estão apresentados na Tabela 3. 
Tabela 3. Densidade relativa aparente, resistência mecânica e ICOM dos briquetes, ICOM da madeira e do carvão.

\begin{tabular}{|c|c|c|c|c|}
\hline & Iaterial & $\begin{array}{l}\text { Densidade } \\
\text { aparente }\end{array}$ & $\begin{array}{c}\text { Resistência } \\
\text { mecânica }\end{array}$ & ICOM \\
\hline Arroz & Casca do grão & $1,077 \mathrm{a}$ & $331,50 a$ & $0,4293 \mathrm{~b}$ \\
\hline & Caule & $0,807 \mathrm{f}$ & $42,26 \mathrm{~g}$ & $0,5757 \mathrm{a}$ \\
\hline Cate & Pergaminho & $0,946 \mathrm{~b}$ & 115,99 e & $0,4546 \mathrm{~b}$ \\
\hline Cann & Bagaço & $0,606 \mathrm{~g}$ & $69,29 \mathrm{f}$ & $0,4418 \mathrm{~b}$ \\
\hline Cana & Palha & $0,841 \mathrm{e}$ & $167,92 \mathrm{~d}$ & $0,4575 \mathrm{~b}$ \\
\hline Foiĩ̃ & Caule & $0,888 \mathrm{c}$ & $282,47 \mathrm{~b}$ & 0,6013 a \\
\hline Feijao & Vagem & $0,944 \mathrm{~b}$ & $79,42 \mathrm{f}$ & $0,6464 \mathrm{a}$ \\
\hline & Serragem & $0,903 \mathrm{c}$ & $190,23 d$ & $0,5501 \mathrm{a}$ \\
\hline Madeira & Maravalha & $0,850 \mathrm{e}$ & - & $0,4435 \mathrm{~b}$ \\
\hline & Caule & $0,846 \mathrm{e}$ & $241,28 \mathrm{c}$ & $0,6384 \mathrm{a}$ \\
\hline Milbo & Folha & $0,936 \mathrm{~b}$ & $236,14 \mathrm{c}$ & $0,4315 \mathrm{~b}$ \\
\hline Ti11no & Palha & $0,822 \mathrm{f}$ & $102,98 \mathrm{e}$ & $0,5971 \mathrm{a}$ \\
\hline & Sabugo & $0,869 \mathrm{~d}$ & $73,99 \mathrm{f}$ & $0,6308 \mathrm{a}$ \\
\hline Soia & Caule & $0,815 \mathrm{f}$ & $223,95 \mathrm{c}$ & $0,4945 \mathrm{~b}$ \\
\hline Soja & Casca vagem & $0,807 \mathrm{f}$ & $34,36 \mathrm{~g}$ & $0,5284 \mathrm{~b}$ \\
\hline Carvão & & - & - & $0,5572 \mathrm{a}$ \\
\hline Madeira & & - & - & $0,5169 \mathrm{~b}$ \\
\hline
\end{tabular}

Os briquetes foram produzidos com tempo de 8 minutos, pressão igual a $153 \mathrm{kgf} \mathrm{cm}^{-2}$ e temperatura ambiente, com exceção dos briquetes feitos a partir de casca de arroz e pergaminho de café, que foram produzidos à temperatura de $125^{\circ} \mathrm{C}$.

Houve diferença estatística para densidade dos briquetes dos diferentes resíduos, tendo o maior valor sido obtido para a casca do arroz, seguido do pergaminho do café, da vagem do feijão e da folha do milho. O menor valor foi para o bagaço de cana (Tabela 3 ).

Os resultados estão de acordo com Quirino \& Brito (1991), que encontraram densidades variando de 0,69 a $0,99 \mathrm{~g} \mathrm{~cm}^{-3}$, para briquetes produzidos com carvão vegetal misturado à serragem, carvão mineral, nitrato, cinzas e aglomerante e superiores aos determinados por Silva (2007), que encontrou densidade aparente média de $0,51 \mathrm{~g} \mathrm{~cm}^{-3}$.
Não foi possível determinar a resistência mecânica dos briquetes feitos a partir de maravalha. Este fato ocorreu porque, na realização do ensaio de compressão, os briquetes deslizaram sobre a base da máquina, o que prejudicou a identificação do momento de ruptura dos mesmos. Ocorria um rearanjamento e o ensaio não era interrompido no momento da ruptura.

A resistência mecânica apresentou resultados distintos estatisticamente. O maior valor encontrado foi para os briquetes produzidos a partir de casca de arroz, que apresentou maior densidade, e o menor, para caule do café, este último de baixa densidade. A Figura 5 representa a relação funcional entre a resistência à compressão e a densidade aparente dos briquetes.

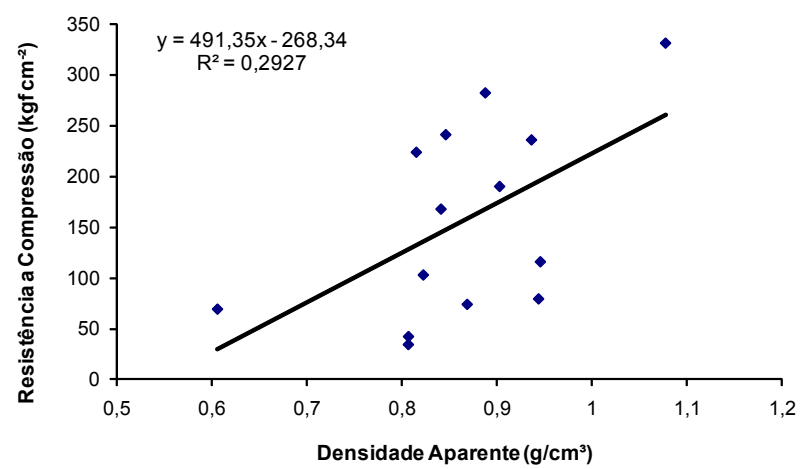

Figura 5. Relação funcional entre a resistência à compressão e a densidade aparente.

Foi possível ajustar um modelo linear da reta que, apesar do baixo coeficiente de determinação, indica um aumento da resistência mecânica em função do aumento da densidade aparente (Figura 5).

Quirino \& Brito (1991), estudando briquetes produzidos com carvão vegetal misturado a serragem, carvão mineral, nitrato, cinzas e aglomerante, encontraram resistência à compressão média de 31,71

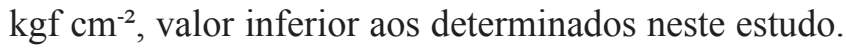
Fontes et al. (1984) encontraram 183,76 kgf cm$~_{-2}, 245,74$ $\mathrm{kgf} \mathrm{cm}^{-2}$ e 229,70 $\mathrm{kgf} \mathrm{cm}^{-2}$, para briquetes produzidos a partir de carvão vegetal e resina termoplástica sintética, resina termoplástica natural e resina termorrígida, respectivamente.

A análise estatística do ICOM dividiu os resíduos em dois grupos (Tabela 4). 
Tabela 4. Grupos de briquetes conforme índice de combustão.

\begin{tabular}{ccll}
\hline Grupo & & Material & ICOM \\
\hline \multirow{4}{*}{$\mathbf{1}$} & Café & Caule & 0,5757 \\
& Feijão & Caule & 0,6013 \\
& Madeira & Vagem & 0,6464 \\
& & Serragem & 0,5501 \\
& Milho & Caule & 0,6384 \\
& & Palha & 0,5971 \\
& Carvão & & 0,6308 \\
\hline \multirow{4}{*}{$\mathbf{2}$} & Arroz & Casca do grão & 0,5572 \\
\hline & Café & Pergaminho & 0,4293 \\
& Cana & Bagaço & 0,4546 \\
& Madeira & Palha & 0,4575 \\
& Milho & Maravalha & 0,4435 \\
& Soja & Folha & 0,4315 \\
& Madeira & Caule & 0,4945 \\
& & & 0,5284 \\
& & & 0,5169 \\
\hline
\end{tabular}

Os resíduos do Grupo 1 apresentaram o mesmo comportamento durante a combustão e foram superiores aos do Grupo 2, pois este último apresentou menor ICOM. A madeira maciça e o carvão, testemunhas do ensaio, foram classificados em grupos diferentes.

Os índices de combustão observados na Tabela 4 estão de acordo com Quirino \& Brito (1991), que encontraram valores variando de 0,31 a 1,23 para briquetes produzidos com carvão vegetal misturado a serragem, carvão mineral, nitrato, cinzas e aglomerante.

Nas Figuras 6 e 7 observam-se o comportamento dos briquetes no combustor em função do tempo de ensaio de combustão do Grupo 1, respectivamente, para a elevação da temperatura e perda de massa. Os briquetes dos materiais do Grupo 1 tiveram seus picos de temperatura em torno de 10 minutos, com exceção da serragem (19 minutos) e do carvão (sem pico definido) (Figura 6). O mesmo ocorreu para a redução de massa (Figura 7); apenas a serragem e o carvão apresentaram comportamento diferenciado. O carvão teve combustão mais estável que os demais materiais, demorou cerca de 120 minutos para atingir a temperatura final de $100{ }^{\circ} \mathrm{C}$ e não apresentou pico definido de temperatura.

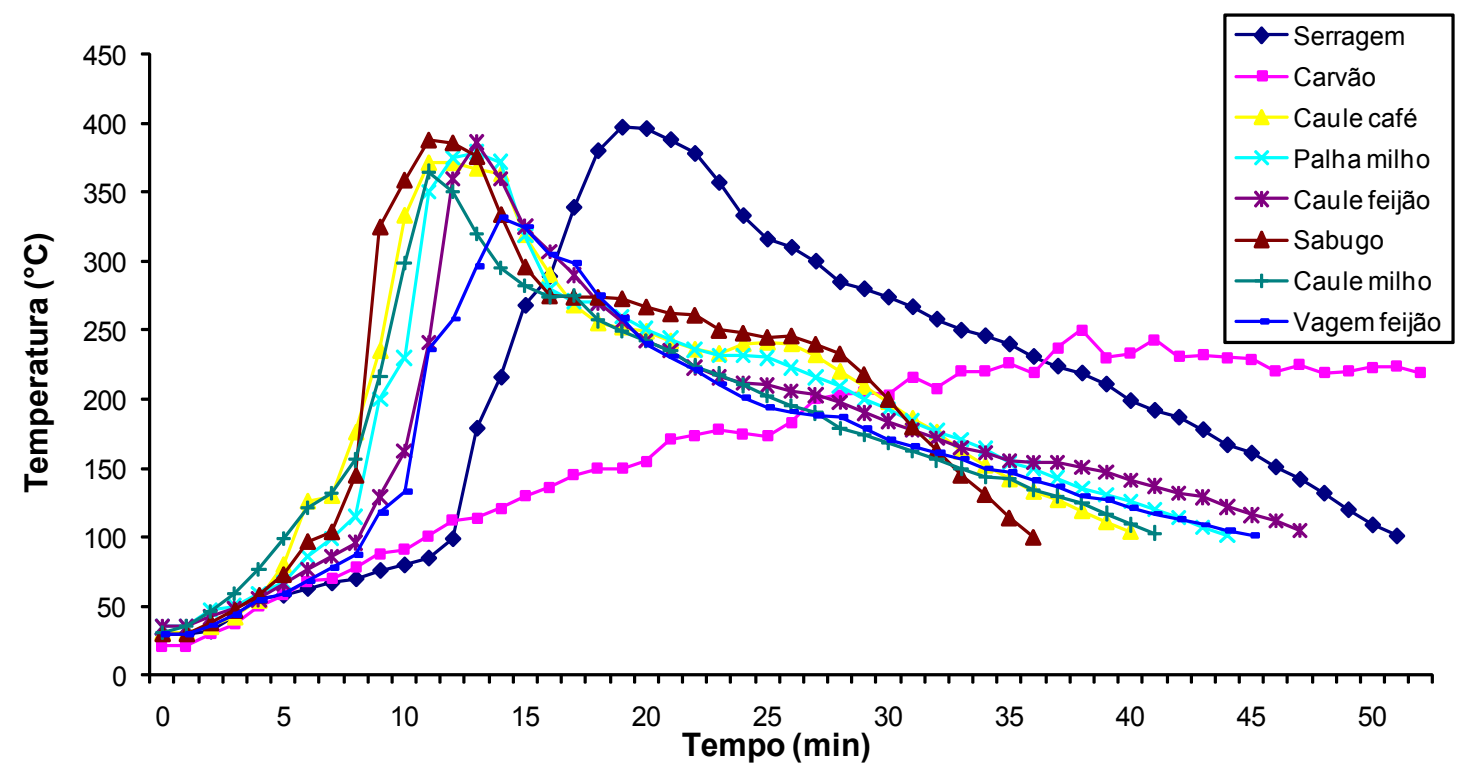

Figura 6. Evolução da temperatura em função do tempo de combustão dos briquetes do Grupo 1. 


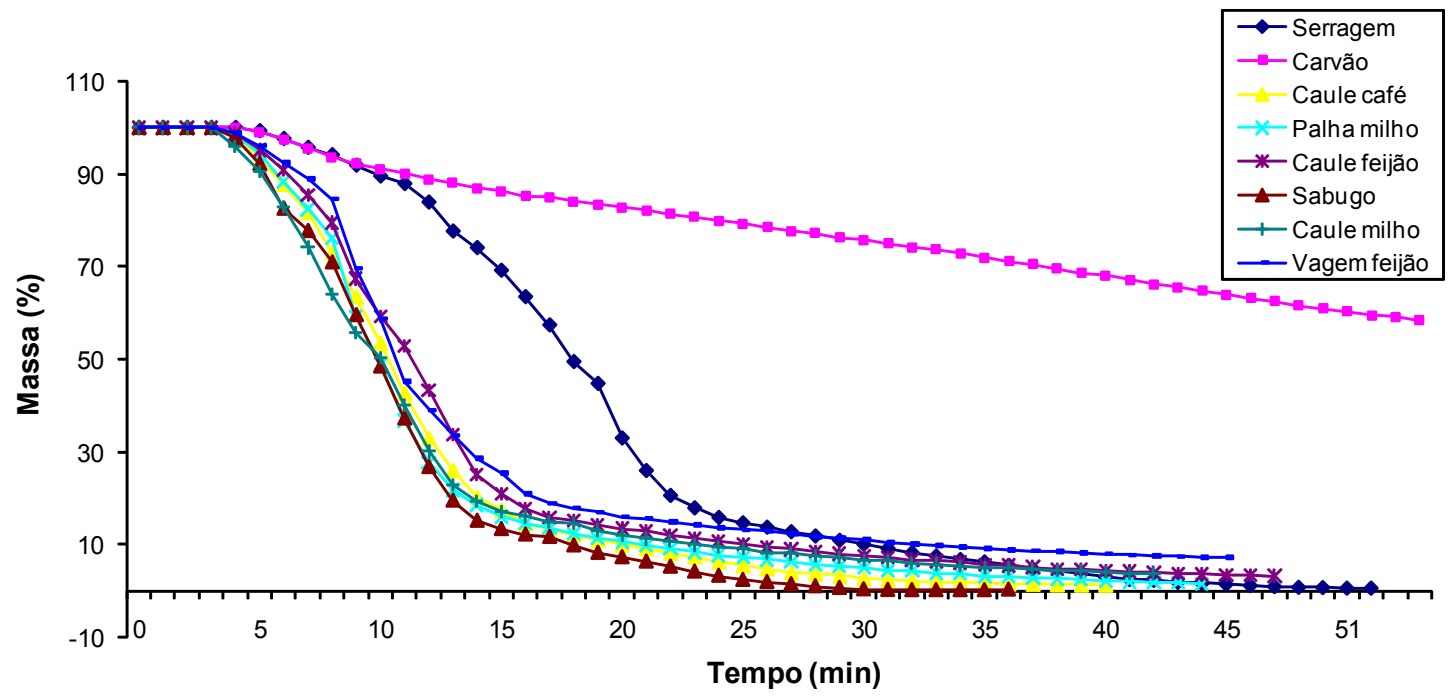

Figura 7. Perda de massa em função do tempo de combustão dos briquetes do Grupo 1.

Nas Figuras 8 e 9 observam-se o comportamento dos briquetes no combustor em função do tempo de ensaio de combustão do Grupo 2, respectivamente, para a elevação da temperatura e perda de massa.

Os briquetes do Grupo 2 apresentaram picos de temperatura em tempos variando dos 9 aos 16 minutos
(Figura 8). O briquete de casca de arroz apresentou perda de massa mais lenta e pico de temperatura mais demorado, aos 16 minutos. Comparando-se os dois grupos, verifica-se que eles apresentaram curvas semelhantes, porém, a combustão dos briquetes do Grupo 2 foi mais homogênea que a do Grupo 1.

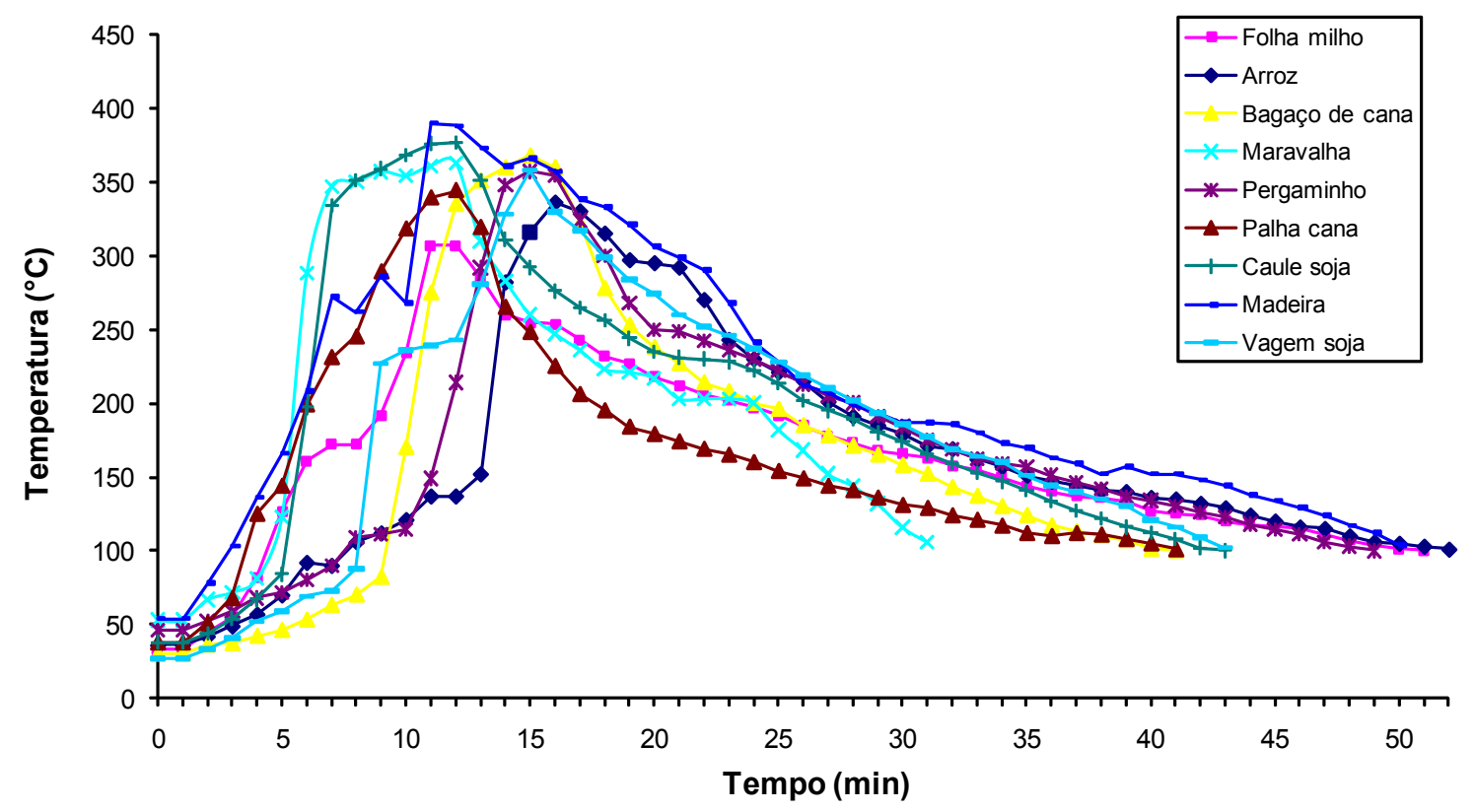

Figura 8. Evolução da temperatura em função do tempo de combustão dos briquetes do Grupo 2. 


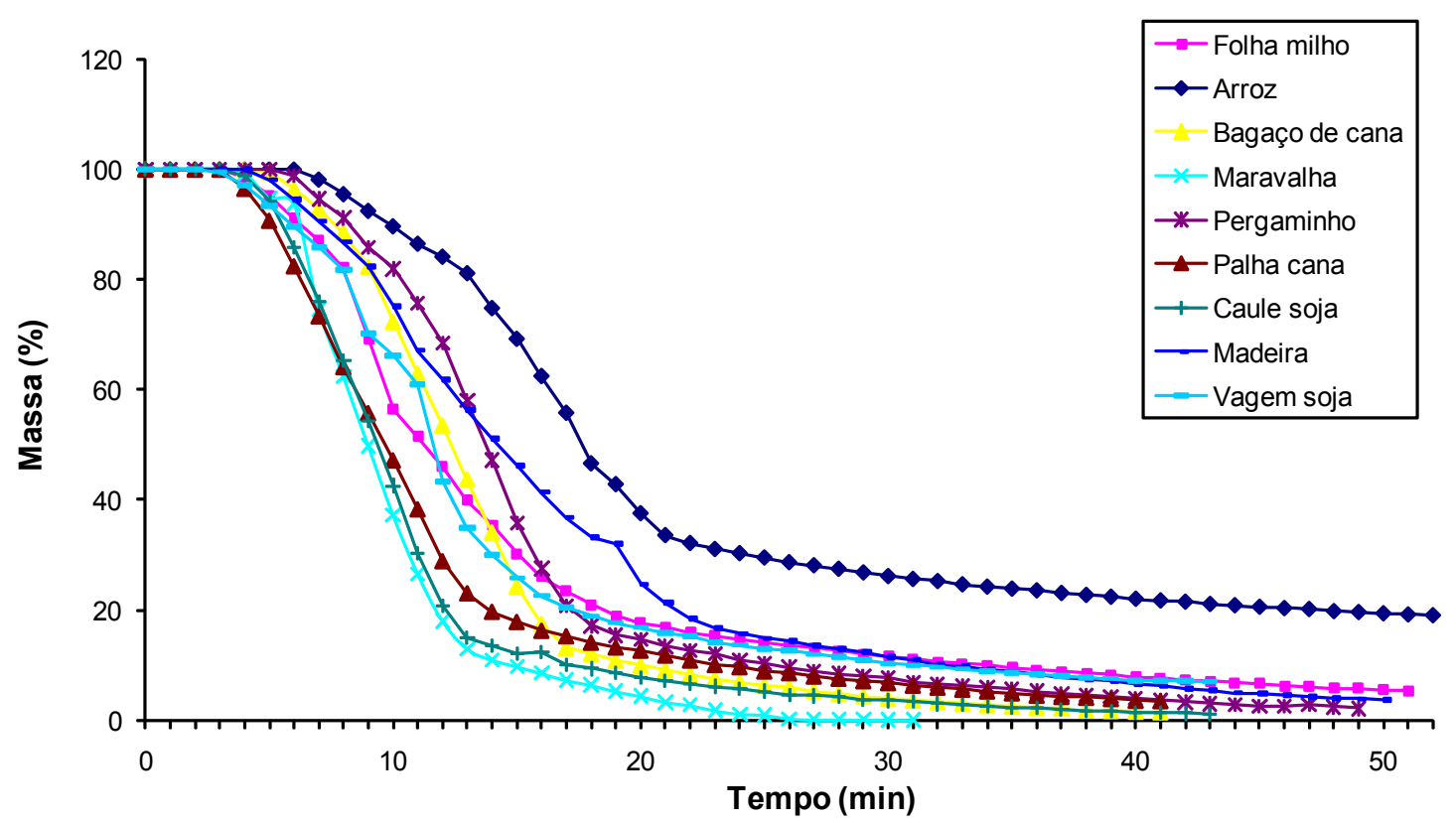

Figura 9. Perda de massa em função do tempo de combustão dos briquetes do Grupo 2.

A Figura 10 mostra a relação funcional entre o ICOM e a densidade aparente dos briquetes. Verifica-se que a relação entre as variáveis foi muito pequena, indicando que o ICOM não sofreu influência da densidade aparente dos briquetes.

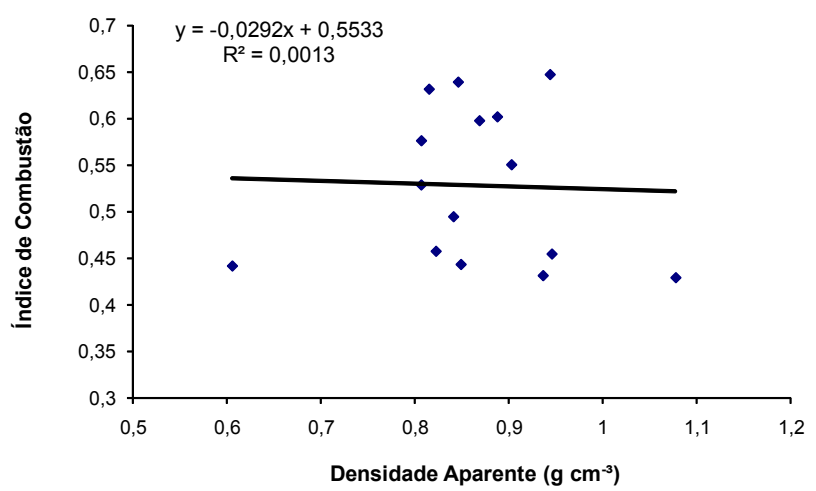

Figura 10. Gráfico do ICOM dos briquetes em função da densidade aparente.

Quirino \& Brito (1991) testaram briquetes de finos de carvão e encontraram correlação apenas entre o índice de combustão e a densidade a granel.

\section{Conclusão}

O tempo e a temperatura de prensagem interferiram na resistência mecânica dos briquetes.

Para briquetes de serragem, o melhor tempo de briquetagem foi de 8 minutos.

A casca de arroz e o pergaminho do café não briquetaram somente com pressão, sem utilização de temperatura.

A temperatura de melhor desempenho foi de $125^{\circ} \mathrm{C}$ para briquetes produzidos a partir de pergaminho do café e casca de arroz.

Encontrou-se correlação de 0,54 entre resistência à compressão e densidade aparente dos briquetes. Entre o índice de combustão, e a densidade aparente a correlação foi praticamente nula.

Os briquetes de casca de arroz apresentaram qualidade superior, devido à sua maior densidade e alta resistência mecânica.

O maior índice de combustão foi encontrado para os briquetes da vagem do feijão. 


\section{Agradecimentos}

À Fundação de Amparo à Pesquisa do Estado de Minas Gerais (Fapemig), ao Conselho Nacional de Desenvolvimento Científico e Tecnológico $(\mathrm{CNPq})$ e à Coordenação de Aperfeiçoamento de Pessoal de Nível Superior (Capes).

\section{Referências}

BRASIL. Empresa de Pesquisa Energética. Balanço Energético Nacional 2010: Ano Base 2009. Rio de Janeiro: EPE, 2010. 276 p.

CHEN, L. J.; XING, L.; HANA, L. Renewable energy from agro-residues in China: solid biofuels and biomass briquetting technology. Renewable \& Sustainable Energy Reviews, Oxford, U.K., v. 13, n. 9, p. 2689-2695, Dec. 2009.
FONTES, P. J. P. de; QUIRINO, W. F.; PASTORE JUNIOR, F.; FILGUEIRAS, S. M. S. Aglutinante para briquetagem de carvão vegetal. Brasília: Instituto Brasileiro de Desenvolvimento Florestal, Laboratório de Produtos Florestais, 1984.

KALIYAN N.; MOREY R.V. Factors affecting strength and durability of densified biomass products. Biomass and Bioenergy, v. 33, n. 3, p. 337-359, Mar. 2009.

QUIRINO, W. F.; BRITO, J. O. Características e índice de combustão de briquetes de carvão vegetal. Brasília: IBAMA, LPF, 1991. 18 p. (Série Técnica, 13).

SCHÜTZ , F. C. A.; ANAMI, M. H.; TRAVESSINI, R. Desenvolvimento e ensaio de briquetes fabricados a partir de resíduos lignocelulósicos da agroindústria. Inovação e Tecnologia, v. 1, n. 1, p. 1-8, 2010.

SILVA, C. A. Estudo técnico-econômico da compactação de resíduos madeireiros para fins energéticos. 2007. $68 \mathrm{f}$.

Dissertação (Mestrado em Engenharia Mecânica) - Universidade Estadual de Campinas, Campinas, SP. 